\section{Immune regulation and colitis: suppression of acute inflammation allows the development of chronic inflammatory bowel disease}

\author{
B Eksteen, L S K Walker, D H Adams
}

Persistent colitis is the result of a balance between local inflammation and regulatory networks. Regulatory $T$ cells have potent anti-inflammatory effects and are likely to be important in the pathogenesis of chronic inflammatory bowel disease

T he success of the gastrointestinal immune system depends on a balance between mounting effective immune responses to pathogenic antigens while suppressing potentially damaging responses against commensal organisms or food antigens. Both the innate and acquired immune system contribute to fighting pathogens. The innate immune system, which includes phagocytes, dendritic cells (DCs), and natural killer (NK) cells, does not require previous exposure to a pathogen and instead relies on evolutionarily ancient pathways such as Toll-like receptors (TLRs) to recognise molecular patterns associated with harmful pathogens. ${ }^{1}$ Different TLRs are able to recognise bacterial products or motifs in viral RNA or DNA. TLR activation triggers an immediate response resulting in the activation of phagocytic mechanisms and the production of cytokines and costimulatory signals that activate the cognate immune response.

The cognate or acquired immune system developed in higher vertebrates to provide a more sophisticated response to a wide variety of antigens. It involves lymphocytes that recognise specific antigens from pathogens processed and presented by specialised antigen presenting cells called DCs. A crucial feature of the cognate immune system is immunological memory whereby a subsequent exposure to the same antigen leads to a more potent and sustained immune response. Antigens from pathogens that penetrate the mucosal barrier are taken up by local DCs and carried via lymphatics to draining mesenteric lymph nodes. ${ }^{2}$ In addition, DCs situated in gut associated lymphoid tissue such as Peyer's patches sample luminal antigens either directly, by extending finger-like processes into the lumen, or via specialised epithelial cells
( $M$ cells) that actively transport luminal antigens to the underlying DCs. ${ }^{3}$ Antigen containing DCs then migrate to secondary lymphoid tissues where they interact with naïve lymphocytes with the appropriate antigenic specificity to generate primed effector lymphocytes expressing the receptors CCR9 and $\alpha 4 \beta 7$ that direct their migration back to gut tissues. ${ }^{4-6}$ Once the antigen is cleared, most effector cells die, leaving a small cohort of long lived memory cells that can rapidly augment immunity to the antigen if encountered again.

The importance of our ability to develop immunity and appropriate responses to gut derived antigens is highlighted by, on one hand, immunodeficient states where persistent gut infections often dominate and translocation of gut pathogens can lead to overwhelming sepsis, and on the other, the fact that inappropriate activation of the intestinal immune system leads to uncontrolled inflammation and inflammatory bowel disease (IBD). ${ }^{7}$ Recent studies suggest that damaging inflammation in IBD is not only the consequence of inappropriate stimulation of effector responses but is also due to a failure of the normal immunosuppressive mechanisms that have evolved to control inflammation in the gut.

The immune system has developed several ways to suppress responses to harmless self or non-pathogenic environmental antigens. Central tolerance is regulated in the thymus where $\mathrm{T}$ cells are selected for survival based on the affinity of their T cell receptor (TCR) for antigens expressed on thymic epithelium and those $\mathrm{T}$ cells showing high affinity for self antigens are deleted. In addition, thymic selection leads to generation of a distinct subset of regulatory $T$ cells $\left(T_{\text {regs }}\right)$ which when activated by antigen can suppress effector responses generated by both NK and T cells in the periphery. ${ }^{8}$ Thymic $\mathrm{T}_{\text {regs, }}$ which comprise approximately $10 \%$ of CD4+ $\mathrm{T}$ cells in the mouse circulation, display several cell surface receptors, including the interleukin (IL)-2 receptor, CD25, and the glucocorticoid induced tumour necrosis factor (TNF) receptor (GITR). They are characterised by expression of the transcription factor Foxp3 which is

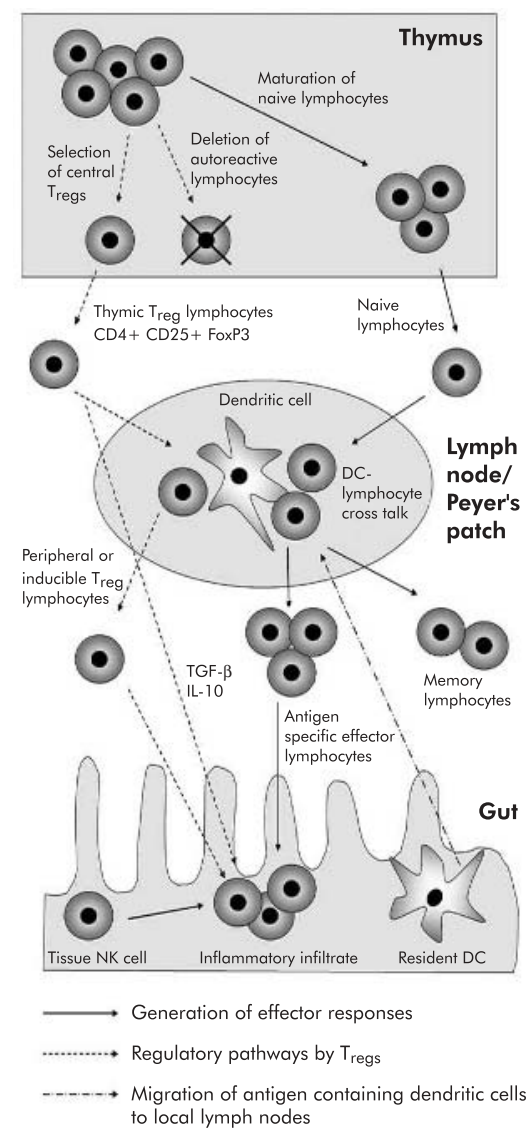

Figure 1 Simplified pathways involved in the generation of effector and regulatory lymphocyte responses. Naive lymphocytes that have been selected and matured in the thymus are able to enter secondary lymphoid tissue such as lymph nodes and Peyer's patches where they interact with dendritic cells (DC) that have assimilated antigens in the gut. Interactions with DCs subsequently prime the naive lymphocytes to the antigen and activate their differentiation into effector lymphocytes. Part of this differentiation is induction of tissue specific homing molecules that direct the effector cells back to the tissue where the antigen was found. During this process memory lymphocytes are also generated to allow for rapid expansion of effector cells if the specific antigen is encountered again. Regulation occurs at several levels with autoreactive lymphocytes being deleted in the thymus and generation of central/ thymic regulatory T cells $\left(\mathrm{T}_{\text {regs }}\right)$. Peripheral or induced $\mathrm{T}_{\text {regs }}$ are also generated locally by DC-lymphocyte interactions. Both sets of $\mathrm{T}_{\text {regs }}$ are able to control inflammation by the production of antiinflammatory cytokines such as transforming growth factor $\beta$ (TGF- $\beta$ ) and interleukin 10 (IL-10). 
critical for $\mathrm{T}_{\text {reg }}$ function, as demonstrated by experiments in which retroviral transfer of Foxp3 to naïve T cells converts them into functional $\mathrm{T}_{\text {regs }}$ whereas its deletion results in loss of regulatory function and the development of autoimmunity. ${ }^{710} \mathrm{~T}_{\text {regs }}$ mediate contact dependent suppression of effector cells in vitro, although in vivo the situation is more complex with IL10 and/or transforming growth factor $\beta$ (TGF- $\beta$ ) being required for suppression in many circumstances. Indeed, it has been reported that $T_{\text {regs }}$ express a membrane bound form of the TGF- $\beta$ cytokine. ${ }^{11}$ In addition to thymic $\mathrm{T}_{\text {regs }}$, inducible $\mathrm{T}_{\text {regs }}$ can be generated in the periphery as a consequence of activation of naïve $\mathrm{T}$ cells by immature DCs or activation in the presence of specific cytokines. Thus generation of inducible $\mathrm{T}_{\text {regs }}$ depends critically on the local microenvironment in which activation takes place. Inducible $\mathrm{T}_{\text {regs }}$ secrete IL-10 and stimulate the local secretion of TGF- $\beta$, both of which are potent regulators of inflammation capable of suppressing the proliferation of effector cells. ${ }^{8}{ }^{12}$

Powrie et al originally defined the importance of $\mathrm{T}_{\text {regs }}$ in gut inflammation, demonstrating that adoptively transferred $\mathrm{T}_{\text {regs }}$ suppress colonic inflammation in experimental colitis and that this suppression depends on both TGF- $\beta^{13}$ and IL-10. ${ }^{14}$ The subsequent demonstration that IL-10 can promote TGF- $\beta$ secretion in the setting of experimental colitis provides a further clue as to how these cytokines may be cooperating in vivo. ${ }^{15}$ The importance of IL-10 is underscored by the fact that deficiency in either IL- $10^{16}$ or in the ability of macrophages/neutrophils to respond to IL-10 (as a result of targeted stat-3 deficiency $)^{17}$ is sufficient to trigger gut pathology. Likewise, removal or inhibition of $\mathrm{T}_{\text {regs }}$ at either the central or peripheral level is associated with autoimmunity, ${ }^{18}$ a break in tolerance, and intestinal inflammation in animal models.

Much of the decision making that leads to generation of peripheral regulatory networks falls upon DCs and suppression and tolerance are the consequences of lymphocyte activation by immature DCs that produce IL-10. ${ }^{19} 20$ Further control of inflammation in the periphery is afforded by the susceptibility of effector lymphocytes to programmed cell death or apoptosis. ${ }^{18}$ Mechanisms that have evolved to control the expansion of antigen specific effector cells are critical for normal immune homeostasis to prevent the uncontrolled proliferation of effector cells. IL-2 is a survival signal for activated lymphocytes which is produced in large amounts during inflammation.
When the antigen has been cleared, IL-2 production falls, resulting in apoptosis of most effector cells except for a small population of long lived memory lymphocytes. ${ }^{21}$ In addition, effector lymphocytes express the death receptor Fas and its ligand Fas-L and once cytolytic $\mathrm{T}$ cells have destroyed Fas bearing target cells, effector T cells can kill each other by the same Fas/FasL interactions allowing inflammation to resolve. Curiously, IL-2 potentiates Fas mediated killing, illustrating the complex interplay that exists between different peripheral tolerance mechanisms. The importance of the Fas pathway is demonstrated by the development of lymphomas in mice that lack either Fas or FasL.

Mechanisms that lead to uncontrolled chronic inflammation in IBD are poorly understood but are likely to involve many if not most of the above mechanisms. ${ }^{22}$ The paper by Westendorf and colleagues $^{23}$ in this issue of Gut, provides further important insights into the mechanisms of chronic inflammation in IBD (see page 60). The authors used a transgenic model in which gut inflammation was triggered by overexpression of a single foreign antigen, influenza HA, in enterocytes. Crossing these mice with transgenic animals that expressed $\alpha \beta$-T cells specific for HA resulted in an animal with autoreactive $\mathrm{T}$ cells that recognised HA as a "self" antigen restricted to the gut. They reported that these animals developed autoimmune colitis and chronic inflammation demonstrating that expression of a self antigen on enterocytes in sufficient to trigger colitis. However, they found that although their model induced chronic inflammation, colitis was far less severe than in other colitis models, suggesting that the inflammation is partially controlled by regulatory mechanisms. The authors then studied the cytokine profiles secreted by mucosal lymphocytes from their transgenic animals in response to antigen stimulation. They found that whereas secretion of the classical Thl effector cytokines interferon $\gamma$ and IL-2 was reduced, secretion of the proinflammatory cytokines TNF- $\alpha$, monocyte chemoattractant protein 1, and IL-6 was increased, indicating that while $\mathrm{T}$ cells were capable of responding to antigen, the nature of the response was markedly altered. This raises the possibility that a balance has developed between regulatory and inflammatory mechanisms giving rise to the generation of chronic persistent inflammation. When the authors pursued this hypothesis further they found that autoreactive lamina propria lymphocytes and intraepithelial lymphocytes expressed increased levels of the anti-inflammatory cytokine IL-10 and several genes associated with the development of regulatory $\mathrm{T}$ cells. While some of these genes would also be highly expressed in activated $\mathrm{T}$ cells (for example, OX40, GITR), others such as neuropilin-1 are thought to specifically identify regulatory cells. ${ }^{24}$ The authors concluded that, in their double transgenic mouse, enterocyte specific $\mathrm{CD} 4+\mathrm{T}$ cells are sufficient to induce colitis which is neither acute and self limiting (which might be expected if regulatory mechanisms were dominant) nor acute and fatal (if they were absent) but rather chronic and persistent. They propose that this outcome is the result of a balance between local inflammatory and regulatory networks and infer that regulatory $\mathrm{T}$ cells may be important in the pathogenesis of chronic inflammation.

Several important conclusions regarding the pathogenesis of IBD can be drawn from the study and there are parallels between the VILLIN-HA ×TCRHA transgenic model of gut inflammation and IBD in humans. Recognition of an autoantigen by either breakdown of central tolerance in the thymus or by acquired cross reactivity to an external antigen provides a potent immune response that is able to establish clinical disease. However, the pattern of disease may well be determined by the nature of the local tolerogenic networks. This is turn will be affected by (1) the genetic background of the individual, which will determine whether they generate strong regulatory or inflammatory responses, and (2) the local microenvironment, including the nature of the bacterial flora. The paper demonstrates the importance of effective thymic selection in deleting autoreactive T cells. This is not a new concept-loss of thymic regulation has been shown to trigger a variety of autoimmune conditions, including colitis-but is nevertheless important as these animals had no obvious defects in the thymus. The authors concede that the transgenic TCR might interfere with thymic selection but it is also plausible that the large numbers of potentially autoreactive lymphocytes in this transgenic model allow some to escape deletion. It is not known if this phenomenon occurs in humans with IBD.

A second important finding is the pattern of inflammation induced in the VILLIN-HA $\times$ TCR-HA mice. Models of colitis induced by agents such as dextran sulphate result in acute inflammation and require repeated administration to mimic chronic gut inflammation whereas the authors' model of autoimmune intestinal inflammation is sustained by the persistent presence of the gut antigen. However, 
the real novelty of the present study is the suggestion that the chronicity of the inflammation, which in many ways resembles clinical IBD, is the result of a balance between pro and anti-inflammatory pathways involving regulatory $\mathrm{T}$ cells. This balance permits continuing inflammation while preventing uncontrolled progression of destructive colitis. Factors underlying this regulatory response are at present unknown although the data in the paper suggest testable theories. The cytokine data suggest that local IL-10 is able to prevent acute destruction of the gut but not chronic intestinal inflammation, leading to persistence of inflammation and chronic disease. Local intestinal DCs are a potential source of IL-10 and may induce the development of IL-10 secreting $\mathrm{T}$ cells. Because the transgenic model expresses local antigen in the absence of an inflammatory "danger" signal, local DCs may be only partially activated, leading to generation of immune responses dominated by IL-10 secretion. The gene expression data suggest that regulatory $\mathrm{T}$ cells are involved, and the nature, localisation, and function of these cells will be important to determine. For instance, are these thymic $T_{\text {regs }}$ or $T_{\text {regs }}$ induced locally by high levels of IL-10 and immature DCs? Is this regulatory network driven by persistent antigen and what is the role if any of gut epithelial cells in maintaining local $\mathrm{T}_{\text {regs }}$ ? The concept that regulatory $\mathrm{T}$ cells are required for the development of chronic inflammation is intriguing and suggests that these cells are more than simple anti-inflammatory agents. The signals that lead to the development and persistence of chronic inflammation are poorly understood and the involvement of regulatory $\mathrm{T}$ cells adds another element to the pathogenesis of chronic inflammatory disease (fig 1).

Gut 2005;54:4-6.

doi: $10.1136 /$ gut.2004.047084

\section{Authors' affiliations}

B Eksteen, L S K Walker, D H Adams, Liver Research Laboratories and MRC Centre for Immune Regulation, Institute for Biomedical Research, Queen Elizabeth Hospital, University of Birmingham, Birmingham, UK

Correspondence to: Professor D H Adams, Liver Research Laboratories, Institute for Biomedical Research, Queen Elizabeth Hospital, University of Birmingham, Birmingham B15 2TT, UK; d.h.adams@bham.ac.uk

Conflict of interest: None declared.

\section{REFERENCES}

1 Aderem A, Ulevitch RJ. Toll-like receptors in the induction of the innate immune response. Nature 2000:406:782-7.

2 Banchereau J, Briere F, Caux C, et al. Immunobiology of dendritic cells. Annu Rev Immunol 2000;18:767-811.

3 Nagler-Anderson C. Man the barrier! Strategic defences in the intestinal mucosa. Nat Rev Immunol 2001;1:59-67.

4 Johansson-Lindbom B, Svensson M, Wurbel MA, et al. Selective generation of gut tropic T cells in gut-associated lymphoid tissue (GALT): requirement for GALT dendritic cells and adjuvant. J Exp Med 2003;198:963-9.

5 Mora JR, Bono MR, Manjunath N, et al. Selective imprinting of gut-homing T cells by Peyer's patch dendritic cells. Nature 2003:424:88-93.

6 Nagler-Anderson C, Terhoust C, Bhan AK, et al. Mucosal antigen presentation and the control of tolerance and immunity. Trends Immunol $2001 ; 22: 120-2$.

7 Nagler-Anderson C, Bhan AK, Podolsky DK, et al. Control freaks: immune regulatory cells. Nat Immunol 2004;5:119-22.

8 Maloy KJ, Salaun L, Cahill R, et al. CD4+CD25+ $T(R)$ cells suppress innate immune pathology through cytokine-dependent mechanisms. J Exp Med 2003;197:111-19.

9 Hori S, Nomura T, Sakaguchi S. Control of regulatory $\mathrm{T}$ cell development by the transcription factor Foxp3. Science 2003;299:1057-61.

10 Khattri R, Cox T, Yasayko SA, et al. An essential role for Scurfin in CD4+CD25+ T regulatory cells. Nat Immunol 2003:4:337-42.
11 Nakamura K, Kitani A, Strober W. Cell contactdependent immunosuppression by CD4(+)CD25(+) regulatory T cells is mediated by cell surface-bound transforming growth factor beta. J Exp Med 2001;194:629-44.

12 Monteleone G, Mann J, Monteleone I, et al. A failure of transforming growth factor-beta 1 negative regulation maintains sustained NFkappaB activation in gut inflammation. $J$ Biol Chem 2004; 279:3925-32.

13 Powrie F, Carlino J, Leach MW, et al. A critical role for transforming growth factor-beta but not interleukin 4 in the suppression of Thelper type 1mediated colitis by CD45RB(low) CD4+ T cells. $J$ Exp Med 1996;183:2669-74.

14 Asseman C, Mauze S, Leach MW, et al. An essential role for interleukin 10 in the function of regulatory $T$ cells that inhibit intestinal inflammation. J Exp Med 1999:190:995-1004.

15 Fuss IJ, Boirivant $M$, Lacy B, et al. The interrelated roles of TGF-beta and IL-10 in the regulation of experimental colitis. J Immunol 2002;168:900-8.

16 Davidson NJ, Leach MW, Fort MM, et al. T helper cell 1-type CD4+ T cells, but not B cells, mediate colitis in interleukin 10-deficient mice. J Exp Med 1996; 184:241-51

17 Takeda K, Clausen BE, Kaisho T, et al. Enhanced Th1 activity and development of chronic enterocolitis in mice devoid of Stat3 in macrophages and neutrophils. Immunity 1999: 10:39-49

18 von Herrath MG, Harrison LC. Antigen-induced regulatory T cells in autoimmunity. Nat Rev Immunol 2003;3:223-32

19 Goddard S, Youster J, Morgan E, et al. Interleukin-10 secretion differentiates dendritic cells from human liver and skin. Am J Pathol 2004; 164:511-19.

20 Bell SJ, Rigby R, English N, et al. Migration and maturation of human colonic dendritic cells. J Immunol 2001;166:4958-67.

21 Akbar AN, Borthwick NJ, Wickremasinghe RG, et al. Interleukin-2 receptor common gammachain signaling cytokines regulate activated $\mathrm{T}$ cell apoptosis in response to growth factor withdrawal: selective induction of anti-apoptotic (bcl-2, bcl-xL) but not pro- apoptotic (bax, bcl-xS) gene expression. Eur J Immunol 1996;26:294-9.

22 Ogura Y, Bonen DK, Inohara N, et al. A frameshift mutation in NOD2 associated with susceptibility to Crohn's disease. Nature 2001;411:603-6.

23 Westendorf AM, Templin M, Geffers R, et al $\mathrm{CD}^{+} \mathrm{T}$ cell mediated intestinal immunity: chronic inflammation versus immune regulation. Gut 2005;54:60-9.

24 Bruder D, Probst-Kepper M, Westendorf AM et al. Neuropilin-1: a surface marker of regulatory $T$ cells. Eur J Immunol 2004;34:623-30.

\section{Will worms really cure Crohn's disease?}

\section{G L Radford-Smith}

Treatment of Crohn's disease patients with the intestinal helminth Trichuris suis appears safe and effective in the short term, even with concurrent immunosuppressive therapy

\section{HELMINTHS AND IBD EPIDEMIOLOGY}

There are a wealth of data that support an immunoregulatory role for helminth infection in animal models and the human host. ${ }^{1-3}$ Recently, this concept has been utilised therapeutically for the treatment of patients with inflammatory bowel disease (IBD). Specifically, Summers and colleagues ${ }^{4}$ report the results of their open study of live Trichuris suis ova therapy in 29 patients with Crohn's disease (CD) in this issue of Gut (see page 87). ${ }^{4}$ Treatment with $T$ suis appears safe and effective in the short term, even with concurrent immunosuppressive therapy. Extension of this concept into the "hygiene hypothesis" 5 may seem increasingly attractive in terms of an explanation for some epidemiological observations in patients with IBD, in particular the north-south gradient for IBD prevalence in both North America and Europe, and the lack of IBD in developing nations. ${ }^{6-8}$ However, some of these epidemiological observations should be viewed with caution. Studies 
that find a north-south gradient are limited to determining incidence rates and do not attempt to tackle the more difficult task of finding epidemiological reasons behind the gradient. In addition, the stringent "rules" that are now being applied to replication of genetic association and linkage studies have not been applied to all epidemiological studies in IBD. Recent data on paediatric IBD and twin studies would support an increasingly important role for environmental factors over genetics. Specifically, paediatric IBD has increased in frequency in the recent past (1990-2001), is becoming increasingly multi-ethnic, and less often familial, and repeat twin studies from Scandinavia using a new (younger) cohort show reduced concordance rates for $\mathrm{CD}^{9}{ }^{9-11}$ Multiple environmental factors, including pathogen exposure, diet, and lifestyle, are likely to contribute to these observations. However, the role of helminth infection is questionable here given the age of these cohorts, their geography, and the switch from ulcerative colitis (UC) to CD as the leading cause of IBD seen in at least two studies. ${ }^{12}$

\section{IS INTESTINAL IMMUNOREGULATION THE EXPLANATION?}

Chronic helminth infection affects over one billion people worldwide, and although these individuals may suffer subsequent nutritional and growth deficiencies, they rarely develop allergic or chronic autoimmune disease. ${ }^{5}$ Immunologically, this is thought to relate to two major processes. Firstly, helminthic infection is associated with a strong Th2 response, which opposes the Thl response associated with autoimmune disease and CD. ${ }^{1-3}$ Secondly, chronic infection with these organisms may generate a network of regulatory $\mathrm{T}$ (Treg) cells that secrete transforming growth factor (TGF)- $\beta$ and interleukin (IL) $-10 .^{213}$ These cytokines may not only regulate aggressive Thl responses but also control heightened Th2 responses that contribute to chronic allergic diseases. The data supporting these pathways come from both human and animal studies, with IL-10 levels elevated in chronic schistosome infection and reduced in patients with chronic allergic diseases from industrialised countries. ${ }^{14}{ }^{15}$ However, there are limited data to confirm the role of these pathways in the human gut. Animal models of IBD such as the trinitrobenzene sulphonic acid colitis murine model have indicated that resolution of inflammation in animals infected with $S$ mansoni eggs is associated with increased mucosal IL-10 and reduced interferon- $\gamma($ IFN- $\gamma)$ mRNA, while IL-4 levels are increased in the mesenteric lymph nodes. ${ }^{16}$ These results are in contrast to those of Moreels et al who used the same model to demonstrate significant attenuation of colitis in animals with helminth infection, but were unable to confirm the Thl to Th2 switch. ${ }^{17}$ Data presented recently in abstract form by Elliott et al indicate that helminth infection ( $H$ polygyrus) in the proximal small bowel is able to influence immunoregulatory cytokines downstream in the Peyer's patches of the terminal ileum. Infection is associated with downregulation of IFN $-\gamma$, upregulation of IL-4, IL-5, and IL-10, and a switch in lipopolysaccharide induced cytokine synthesis, from IL-12 to TGF- $\beta^{18} 19$ All of these experiments have the limitations of being carried out in the highly controlled environment of animal models, and some also involve a cell isolation step. No similar human data are available. However, experience has taught us that human IBD is not as simple as Thl versus Th2,, ${ }^{20}$ and therefore other "anticolitis" mechanisms of protection and repair may be in place during helminth infection. It is not so long ago that the concept of a breakdown in oral tolerance was put forward as a potential mechanism for human chronic inflammatory disorders, including IBD. This hypothesis has a very similar cast of cytokines, including IFN- $\gamma$, IL-2, IL- 4 , IL-10, and TGF- $\beta$. Successful trials of promoting oral tolerance in animal models are yet to realise their potential in patients. ${ }^{21}$

\section{OTHER PROTECTIVE MECHANISMS}

Helminth infection may bring other anticolitis mechanisms into play, including increases in mucus and water secretion into the gut lumen via effects on goblet cells and mast cell activation. ${ }^{22}{ }^{23}$ This may influence the interaction between gut bacteria, their products, and a diseased epithelium, as well as impacting on intestinal motility. Helminths may also influence the microbial ecology of the gut ${ }^{24}$ and the neuroendocrine response, with an increase in neurotransmitters such as vasoactive intestinal polypeptide. ${ }^{25}$ None of these factors has been assessed in human studies.

\section{WIDENING THE CONCEPT OF PATHOGEN EXPOSURE IN IBD}

There are other "pathogens" that may give us clues to a more complex interplay between the environment and the human host in IBD. A number of studies show a reciprocal relationship between exposure to Helicobacter pylori and IBD, particularly CD. ${ }^{26}{ }^{27}$ At least two studies have gone on to demonstrate that $H$ pylori exposure may be associated with subtle changes in disease course, including a delay in $\mathrm{CD}$ presentation ${ }^{28}$ and a reduction in relapses in non-smokers with $\mathrm{CD}_{,}{ }^{29}$ despite the known mucosal Thl response associated with $H$ pylori infection. ${ }^{30}$ These studies have thus far been relatively small and some of the results may be due to a cohort effect. However, the results are consistent with increased levels of domestic hygiene in CD patients, and $H$ pylori in this situation may be a surrogate marker of the spectrum of environmental exposures in infancy and childhood. Similar exposure data are not available for helminth infection in the IBD population. Data are available for allergic disease and exposure to Enterobius vermicularis within a similar "developed world" population, and do not show any protective effect of infection over allergy. ${ }^{31}$ However, "infection turnover", as opposed to specific infections, may also play an important role in the development of a balanced immune system by generation of increased regulatory T cells. An example of this may be childhood/adolescent appendicitis and its potentially protective role against the development of UC. ${ }^{32}$ There are two further pieces of recent evidence that indirectly support the concept of reduced pathogen exposure in childhood as a risk factor for IBD. Baron et al identified breast feeding as being an independent risk factor for the development of paediatric CD. ${ }^{33}$ This may work in a number of ways, one of which is to provide the infant with blocking antibody to an array of dietary and microbial antigens and thus reduce both oral tolerance and pathogen exposure at a critical stage of immunological development. Secondly, analysis of the mucosa associated bacteria of patients with active IBD and controls suggests that patients have a reduction in the diversity of intestinal bacteria compared with the control group. ${ }^{34}$ However, this may be confounded by a greater uptake of antibiotics in patients with $\mathrm{CD}$, as recently reported in Gut. ${ }^{35}$ Both of these studies $^{33}{ }^{34}$ need to be replicated by independent investigators. These observations together with the results of helminth infection suggest that the microbial environment of the entire gut may have an influence on the development of intestinal inflammation. Further work on the epidemiology of these early exposures and the microbial ecology of the whole gut are essential in identifying key environmental risk and protective factors for IBD.

\section{IS THERAPEUTIC HELMINTH INFECTION SAFE?}

Complications related to therapeutic helminth infection have not arisen thus 
far. However, there is evidence that coinfection with other known pathogens such as Campylobacter jejuni may result in serious infection, including septicaemia. ${ }^{36}$ A recent case report indicates that this coinfection and its serious consequences may also occur in patients. ${ }^{37}$ Another potentially serious coinfection is S mansoni with Toxoplasma gondii, which leads to a significant increase in circulating tumour necrosis factor $\alpha$, severe liver pathology, and death in a murine model. ${ }^{38}$ These reports indicate that patients being considered for helminth therapy may require screening for carriage of other potential pathogens prior to initiation of treatment. Other issues related to this that need to be addressed by future studies are the choice of organism and the type of infection. Both human and animal studies indicate that a heavy helminth burden is associated with a greater immunoregulatory environment, while a light burden may be associated with an increased risk of allergic disease. ${ }^{5}$ The current human trials in IBD patients use a transient infection and, despite this, demonstrate clinical efficacy and no significant allergic disease postinfection. ${ }^{4}$ Long term data, particularly after repeated exposure, will provide further reassurance.

\section{SUMMARY}

In conclusion, helminth infection provides us with an excellent model of a successful parasite which is able to manipulate its environment within the host to its advantage. Summers and colleagues ${ }^{4}$ have now taken that further by using helminths to gain an advantage for the host. It is too early to determine whether this form of treatment will be safe and effective for larger numbers of patients with IBD-further controlled randomised studies will be required to answer this. However, what these important and innovative studies demonstrate is the need for a greater understanding of the helminth-host relationship. This is slowly being addressed but almost exclusively in animal models. Of special interest will be identification of antigens or epitopes responsible for the generation of a tolerant environment, and recent work indicates that one candidate is the schistosome oligosaccharide lacto- $\mathrm{N}$ neotetraose. ${ }^{39}$ This molecule, which is also present in human milk, stimulates the expansion of $\mathrm{a} \mathrm{Grl}^{+}$cell population, which creates a Th2 biased immune environment by increased production of IL-10 and TGF- $\beta$, and by directing naïve $\mathrm{CD}^{+} \mathrm{T}$ cells down the Th2 path. Molecules such as this may represent potentially novel therapeutic agents for chronic inflammatory disorders such as
IBD, and thus bypass the need for helminth inoculation and infection.

Gut 2005;54:6-8.

doi: $10.1136 /$ gut.2004.044917

Correspondence to: Dr G Radford-Smith, Department of Gastroenterology, Level 9A, Ned Hanlon Building, Royal Brisbane and Women's Hospital, Herston 4029, Australia; graham_radford-smith@health.qld.gov.au

Conflict of interest: None declared.

\section{REFERENCES}

1 Williams ME, Montenegro S, Domingues AL, et al. Leucocytes of patients with Schistosoma mansoni respond with a $\mathrm{T}_{\mathrm{h}} 2$ pattern of cytokine production to mitogen or egg antigens but with a $\mathrm{T}_{h} 0$ pattern to worm antigens. J Infect Dis 1994; 170:946-54.

2 Satoguina J, Mempel M, Larbi J, et al. Antigenspecific T regulatory-1 cells are associated with immunosuppression in a chronic helminth infection (onchocerciasis). Microbes Infect 2002;4:1291-300.

3 Doetze A, Satoguina J, Burchard G, et al. Antigen-specific cellular hypo-responsiveness in a chronic human helminth infection is mediated by $\mathrm{T}_{h} 3 / \mathrm{T}_{\mathrm{r}} 1$-type cytokines $\mathrm{IL}-10$ and transforming
growth factor- $\beta$ but not by a $\mathrm{T}_{h} 1$ to $\mathrm{T}_{h} 2$ shift. Int growth factor- $\beta$ but not by

4 Summers RW, Elliott DE, Urban JF, et al. Trichuris suis therapy in Crohn's disease. Gut 2005;54:87-90.

5 Yazdanbakhsh M, Kremsner PG, van Ree R. Allergy, parasites and the hygiene hypothesis. Science 2002:296:490-4.

6 Sonnenberg A, McCarty DJ, Jacobsen SJ. Geographic variation of inflammatory bowel disease within the United States. Gastroenterology 1991; 100:143-9.

7 Shivananda S, Lennard-Jones J, Logan R, et al. Incidence of inflammatory bowel disease across Europe: is there a difference between north and south? Results of the European collaborative study on inflammatory bowel disease (EC-IBD). Gut 1996:39:690-7

8 Hutt MS. Epidemiology of chronic intestinal disease in middle Africa. Isr J Med Sci 1979;15:314-17

9 Kugathasan S, Judd RH, Hoffman RG, et al. Epidemiologic and clinical characteristics of children with newly diagnosed inflammatory bowel disease in Wisconsin: a statewide populationbased study. J Pediatr 2003;143:525-31.

10 Armitage E, Drummond $\mathrm{H}$, Ghosh $\mathrm{S}$ et al. Incidence of juvenile-onset Crohn's disease in Scotland. Lancet 1999;353:1496-7.

11 Halfvarson J, Tysk C, Jarnerot G. Decreasing pair concordance in monozygotic twins with Crohn's disease. Gastroenterology 2004;126(suppl 2):A45

12 Hildebrand H, Finkel Y, Grahnquist L, et al. Changing pattern of paediatric inflammatory bowel disease in northern Stockholm 19902001. Gut 2003:52:1432-4.

13 King CL, Medhat A, Malhotra l, et al. Cytokine control of parasite-specific anergy in human urinary schistosomiasis. IL-10 modulates lymphocyte reactivity. J Immunol 1996;156:4715-21.

14 Mahanty S, Nutman TB. Immunoregulation in human lymphatic filariasis: the role of interleukin 10. Parasite Immunol 1995; 17:385-92.

15 Borish L, Aarons A, Rumbyrt J, et al. Interleukin10 regulation in normal subjects and patients with asthma. J Allergy Clin Immunol 1996:97:1288-96.

16 Elliott DE, Li J, Blum A, et al. Exposure to schistosome eggs protects mice from TNBS induced colitis. Am J Physiol Gastrointest Liver Physiol 2003;284:G385-91.

17 Moreels TG, Nieuwendijk RJ, De Man JG, et al Concurrent infection with Schistosoma mansoni attenuates inflammation, induces changes in colonic morphology, cytokine levels, and smooth muscle contractility of trinitrobenzene sulphonic acid induced colitis in rats. Gut 2004;53:99-107.

18 Elliott DE, Setiawan T, Metwali A, et al. Intestina helminthes induce lamina propria T cell IL-10, which inhibits mucosal interferon- $\gamma$ production. Gastroenterology 2004; 126(suppl 2):A280.

19 Nedim Ince M. Setiawan T, Blum A, et al. Helminths modulate mucosal $T$ cell responsiveness to LPS promoting TGF- $\beta$ production. Gastroenterology 2004;126(suppl 2):A576

20 Van Deventer SJH, Elson CO, Fedorak RN, et al. Multiple doses of intravenous interleukin 10 in steroid-refractory Crohn's disease.

Gastroenterology 1997;113:383-9.

21 Mayer L, Shao L. Therapeutic potential of oral tolerance. Nat Rev Immunol 2004;4:407-19.

22 Else KJ, Finkelman FD. Intestinal nematode parasites, cytokines and effector mechanisms. Int J Parasitol 1998;28:1145-58.

23 Stead RH, Tomioka M, Quinonez G, et al. Intestinal mucosal mast cells in normal and nematode-infected rat intestines are in intimate contact with peptidergic nerves. Proc Natl Acad Sci U S A 1987;84:2975-9

24 Dwinell MB, Bass P, Schaefer DM, et al. Tapeworm infection decreases intestinal transit and enteric aerobic bacterial populations. Am J Physiol Gastrointest Liver Physiol 1997;273:G480-5.

25 McKay DM, Fairweather I. A role for the enteric nervous system in the response to helminth infections. Parasitol Today 1997;13:63-9.

26 Halme L, Rautelin H, Leidenius $M$, et al. Inverse correlation between Helicobacter pylori infection and inflammatory bowel disease. J Clin Pathol 1996:49:65-7

27 Feeney MA, Murphy F, Clegg AJ, et al. A casecontrol study of childhood environmental risk factors for development of inflammatory bowel disease. Eur J Gastroenterol Hepatol 2002; 14:529-34.

28 Vare PO, Heikius B, Selvennoinen JA, et al. Seroprevalence of Helicobacter pylori infection in inflammatory bowel disease: is Helicobacter pylori infection a protective factor? Scand J Gastroenterol 2001;36:1295-300.

29 Puspok A, Dejaco C, Oberhuber G, et al. Influence of Helicobacter pylori infection on the phenotype of Crohn's disease. Am J Gastroenterol 1999:94:3239-44

30 Bamford KB, Fan X, Crowe SE, et al. Lymphocytes in the human gastric mucosa during Helicobacter pylori have a T helper cell 1 phenotype. Gastroenterology 1998; 114:482-92.

31 Herrstrom P, Henricson KA, Raberg A, et al. Allergic disease and the infestation of Enterobius vermicularis in Swedish children 4-10 years of age. J Investig Allergy Clin Immunol 2001;11:157-60.

32 Radford-Smith GL. The role of the appendix and appendectomy in patients with IBD. IBD Monitor 2003;4:120-8.

33 Baron S, Gower-Rousseau C, Merle V, et al. Environmental risk factors in inflammatory bowel disease: A pediatric population-based casecontrol study in northern France. Gut 2003;52(Suppl VI):A39

34 Ott SJ, Musfeldt M, Wenderoth DF, et al. Reduction in diversity of the colonic mucosa associated bacterial microflora in patients with active inflammatory bowel disease. Gut 2004;53:685-93

35 Card T, Logan RF, Rodrigues LC, et al. Antibiotic use and the development of Crohn's disease. Gut 2004:53:246-50.

36 Mansfield LS, Gauthier DT, Abner SR, et al. Enhancement of disease and pathology by synergy of Trichuris suis and Campylobacter jejuni in the colon of immunologically naive swine. Am J Trop Medical Hyg 2003:68:70-80.

37 Shin JL, Gardiner GW, Deitel W, et al. Does whipworm increase the pathogenicity of Campylobacter jejuni: A clinical correlate of an experimental observation. Can J Gastroenterol 2004;18:175-7.

38 Marshall AJ, Brunet LR, van Gessel Y, et al. Toxoplasma gondii and Schistosoma mansoni synergize to promote hepatocyte dysfunction associated with high levels of plasma TNF-a and early death in C57BL/6 mice. J Immunol $1999 ; 163: 2089-97$

39 Terrazas LI, Walsh KL, Piskorska D, et al. The schistosome oligosaccharide lacto- $\mathrm{N}$-neotetraose expands $\mathrm{Gr} 1+$ cells that secrete anti-inflammatory cytokines and inhibit proliferation of naïve CD4+ cells: A potential mechanism for immune polarization in helminth infections. J Immunol $2001 ; 167: 5294-303$. 


\section{Resistance to lamivudine therapy: is there more than meets the eye?}

\section{G Dusheiko, A Bertoletti}

\section{A CD8+ T cell response to lamivudine resistant polymerase cytotoxic T lymphocyte (CTL) epitope influences the response to lamivudine treatment for chronic hepatitis B and may indicate an important aspect of the role of $\mathrm{T}$ cell responsiveness in lamivudine therapy}

$\mathrm{T}$ he goals of treatment of hepatitis B are to prevent progression of the disease or to slow the disease process. Hepatitis B virus (HBV) is a DNA virus which integrates into the host genome. Thus it is difficult to eradicate viraemia. However, it is possible, albeit in a minority, to reduce levels of viraemia to relatively low threshold levels after finite courses of treatment with either interferon alpha or nucleoside analogues, and to lessen the induced necroinflammatory and immune response. ${ }^{1}$ Two major forms of active chronic hepatitis $\mathrm{B}$ are recognised: wild-type (or hepatitis B e antigen (HBeAg) positive chronic $\mathrm{HBV}$ infection) and anti-HBe positive or precore mutant disease. The latter disease is caused by variants of HBV that contain nucleotide substitutions in the core promoter/precore regions of the viral genome. ${ }^{2}$

Wild-type (HBeAg positive) chronic hepatitis B can be treated with either interferon alpha or nucleoside analogues. Loss of HBeAg and associated suppression of viral replication with pegylated interferon alpha and new nucleoside analogues such as lamivudine, adefovir, tenofovir, telbuvidine, entecavir, and emtricitabine leads to biochemical remission, histological improvement, and in a small percentage, loss of HBsAg. ${ }^{3-5}$ Durable responses can occur. Continuous therapy is frequently required for the majority of anti-HBe positive patients with chronic hepatitis B. Thus in most patients, longer term therapy is required to suppress viral replication and thereby slow the disease process.

Therapy with lamivudine alone to suppress viral replication, leading to normalisation of alanine aminotransferase (ALT) levels and improvements in liver histology, unfortunately leads to the emergence of lamivudine resistant mutants in over $50 \%$ of treated patients within three years of treatment. ${ }^{6}$ The immediate clinical impact of resistance is usually relatively minor, although ALT flares and hepatic decompensation can occur. ${ }^{8}$ Earlier short term studies suggested that resistant HBV mutants were less fit (that is, were less replication competent) and consequently less pathogenic. Subsequent studies have indicated that incomplete suppression of $\mathrm{HBV}$ replication reduces the degree of benefit. Drug resistant virus favours the selection of increasingly fit and equally pathogenic virus by viral adaptation, and given the complex immune response to hepatitis $\mathrm{B}$, such variants are indeed pathogenic over time. ${ }^{9-12}$ Resistance to lamivudine results in lower seroconversion rates in HBeAg positive patients, lower rates of virological and biochemical remission, and less favourable histological change and thus an adverse effect on treatment outcome. $^{13}$

Lamivudine resistance has been mapped to mutations in the tyrosinemethionine-aspartate-aspartate (YMDD) motif of the reverse transcriptase (rt) domain of HBV DNA polymerase. ${ }^{14}$ Methionine 204 is mutated to isoleucine or valine (rtM204I/V) in patients with increasing viraemia. Although predictors of resistance have been incompletely defined, immunosuppressant therapy, precore mutants or core promoter variants, duration of therapy, higher baseline ALT, higher baseline HBV DNA, body mass index, and HBV subtype adw have all been implicated. ${ }^{15}$ Mutational patterns may also differs between genotypes $\mathrm{A}$ and D. ${ }^{16}$

Lamivudine treatment have been shown to enhance CD4 and CD8-T cell response to $\mathrm{HBV}$ antigens. ${ }^{17}{ }^{18}$ In this issue of Gut, Lin and colleagues ${ }^{19}$ suggest that a CD8+ $\mathrm{T}$ cell response to lamivudine resistant polymerase epitope influences the response to lamivudine (see page 152). They examined the function and phenotype of specific $\mathrm{T}$ cells and demonstrated that functional
anti-YMDD cytotoxic $\mathrm{T}$ lymphocytes (CTL) correlated with response and outcome. The authors capitalised on the fact that the YMDD motif of the rt domain of HBV DNA polymerase within the nonapeptide YMDDVVLGA (amino acid residues 203-211) in the catalytic site of the HBV DNA polymerase, is an HLA-A2-restricted CTL epitope. ${ }^{20}$ Thus quantitative measurement of the numbers of peptide specific CTLs is feasible by MHC tetramer-peptide complex staining. The peptides used for analysis included the dominant HLA-A2 restricted peptide from the HBcAgl827 (FLPSDFFPSV), the wild-type YMDD motif nonapeptide (YMDDVVLGA), the mutant YVDD peptides (YVDDVVLGA), and YIDD peptide (YIDDVVLGA), to construct HLA-A2-peptide tetrameric complexes.

The authors demonstrated that the frequency of YMDD, YIDD, and YVDD motif specific tetramer positive cells within the HLA-A2 CD8 T cell population was increased in "sustained responders" (that is, those with clearance of HBeAg and sustained normalisation of ALT after the end of lamivudine therapy) but not in "nonresponders". The interesting scenario proposed by the authors is that these anti-mutant CTLs may also contribute to clearance of emerging mutant viruses and a successful response to lamivudine treatment. The implication is that treatment responses are improved (and conversely rates of resistance reduced) if CD8+ T cells respond to treatment and proliferate, resulting in a higher level of functional anti-mutant CTL activity during and after therapy.

Some aspects however need to be considered. Firstly, the HBV specific CD8+ T cells were detected in this study only after repetitive in vitro expansion, a technique that detects a small number of precursors. Thus the frequency of polymerase specific CD8+ cells was lower than frequencies usually detected in patients controlling $\mathrm{HBV}$ infection. ${ }^{21}$ In addition, the in vivo antiviral efficacy of polymerase specific CD8 $+\mathrm{T}$ cells is under debate. The ability of polymerase specific CD8+ cells to control viral replication seems absent in HBV transgenic mice ${ }^{22}$ and in patients with chronic hepatitis B. ${ }^{21}$ Thus the increased presence of YMDD, YIDD, and YVDD specific CD8+ cells might be merely an association, and not the primary basis of the sustained response to lamivudine treatment. Other CD8+ $\mathrm{T}$ cells, not necessarily polymerase specific, could be present in sustained responders to control viral replication.

The ability of YMDD specific CTLs to cross react with YIDD and YVDD mutant epitopes is also not totally unexpected. 
As the authors point out in their discussion, the amino acid substitution in the YMDD epitope is located at position 204, which corresponds to the anchor position of the epitope and does not affect $\mathrm{T}$ cell recognition. Thus demonstration that YMDD specific CTLs can be activated by YIDD and YVDD mutant epitopes shows that the isoleucine and valine mutations at position 204 do not abrogate the binding of the epitope to HLA-A2, and that recognition of lamivudine resistant mutant epitopes does not require induction of a new cross reactive CTL response. However, it must be considered that these mutations might have an impact on the immunogenicity of the YMDD region. It will be important, for example, to directly test whether these YIDD or YVDD lamivudine resistant epitopes bind with higher affinity than YMDD to HLA-A2 molecules. Improved binding of the mutant peptide to HLAclass I molecules would increase the presentation of the lamivudine resistant epitope to specific CTL. This could potentially enhance the ability of polymerase specific CD8+ cells to recognise HBV infected cells in vivo and thus explain the association of polymerase specific CD8 and sustained viral control during lamivudine treatment in HLAA2+ patients.

Demonstration that polyclonal activation of anti-wild type and CTL specific immune responses to YMDD, YIDD, and YVDD epitopes correlates with treatment outcome is an intriguing and new finding, and may point to an important aspect of the role of $\mathrm{T}$ cell responsiveness in lamivudine therapy. If confirmed, these new findings may assist in devising a strategy for treatment of patients and recognition of patterns of genotypic and phenotypic resistance. Lamivudine is a useful treatment for chronic hepatitis B, but its usefulness as a single therapy is limited by the frequency with which resistance occurs. It will be important to ascertain how treatment outcomes can be improved by further insights into immune responsiveness during antiviral therapy.

Gut 2005;54:9-10.

doi: $10.1136 /$ gut.2004.047548

\section{Authors' affiliations}

G Dusheiko, A Bertoletti, Centre for Hepatology and Institute for Hepatology, Royal Free and University College School of Medicine, London, UK

Correspondence to: Professor G Dusheiko, Centre for Hepatology and Institute for Hepatology, Royal Free and University College School of Medicine, Pond St, London HA5 1DE, UK; g.dusheiko@rfc.ucl.ac.uk

Conflict of interest: None declared.

\section{REFERENCES}

1 Maini MK, Boni C, Lee CK, et al. The role of virusspecific $C D 8^{+}$cells in liver damage and viral control during persistent hepatitis $B$ virus infection. J Exp Med 2000;191:1269-80.

2 Hadziyannis SJ, Vassilopoulos D. Hepatitis B e antigen-negative chronic hepatitis $B$. Hepatology 2001;34:617-24.

3 Dusheiko GM. Interferon alpha: Biology, pharmacology and therapy for chronic viral hepatitis. In: Thomson AW, Lotze MT, eds. The cytokine handbook. London: Elsevier Science, 2003: 1233-54.

4 Lok AS, Heathcote EJ, Hoofnagle JH. Management of hepatitis B: 2000-Summary of a workshop. Gastroenterology 2001; 120:1828-53.

5 Keeffe EB, Dieterich DT, Han SH, et al. A treatment algorithm for the management of chronic hepatitis B virus infection in the United States. Clin Gastroenterol Hepatol 2004;2:87-106

6 Perrillo RP. How will we use the new antiviral agents for hepatitis B? Curr Gastroenterol Rep 2002;4:63-71.

7 Dusheiko G. A pill a day, or two, for hepatitis B? Lancet 1999;353:1032-3.

$8 \mathrm{Kim}$ JW, Lee HS, Woo GH, et al. Fatal submassive hepatic necrosis associated with tyrosinemethionine-aspartate-aspartate-motif mutation of hepatitis $B$ virus after long-term lamivudine therapy. Clin Infect Dis 2001;33:403-5.
9 Wiegand J, Tischendorf JJ, Nashan B, et al. Severe exacerbation of chronic hepatitis B after emergence of lamivudine resistance in a cirrhotic patient: immediate switch to adefovir dipivoxil appears to be indicated. Z Gastroenterol 2004;42:15-18.

10 Dienstag JL, Goldin RD, Heathcote EJ, et al. Histological outcome during long-term lamivudine therapy. Gastroenterology 2003;124:105-17.

11 Dienstag JL, Cianciara J, Karayalcin S, et al. Durability of serologic response after lamivudine treatment of chronic hepatitis B. Hepatology 2003;37:748-55.

12 Bock CT, Tillmann HL, Torresi J, et al. Selection of hepatitis $B$ virus polymerase mutants with enhanced replication by lamivudine treatment after liver transplantation. Gastroenterology 2002;122:264-73.

13 Leung NWY, Lai CL, Chang TT, et al. Extended lamivudine treatment in patients with chronic hepatitis B enhances hepatitis B e antigen seroconversion rates: Results after 3 years of therapy. Hepatology 2001 33:1527-32.

14 Ling R, Mutimer D, Ahmed N, et al. Selection of mutations in the hepatitis $B$ virus polymerase during therapy of transplant recipients with lamivudine. Hepatology 1996;24:711-13.

15 Zollner B, Petersen J, Schafer P, et al. Subtypedependent response of hepatitis $B$ virus during the early phase of lamivudine treatment. Clin Infect Dis 2002;34: 1273-7.

16 Zollner B, Petersen J, Puchhammer-Stockl E, et al. Viral features of lamivudine resistant hepatitis $B$ genotypes A and D. Hepatology 2004;39:42-50.

17 Boni C, Bertoletti A, Penna A, et al. Lamivudine treatment can restore $T$ cell responsiveness in chronic hepatitis B. J Clin Invest 1998;102:968-75

18 Boni C, Penna A, Ogg GS, et al. Lamivudine treatment can overcome cytotoxic T-cell hyporesponsiveness in chronic hepatitis B: New perspectives for immune therapy. Hepatology 2001;33:963-71.

19 Lin C-L, Tsai S-L, Lee TH, et al. High frequency of functional anti-YMDD and -mutant cytotoxic T lymphocytes after in vitro expansion correlates with successful response to lamivudine therapy for chronic hepatitis B. Gut 2005;54:152-61.

20 Rehermann B, Fowler P, Sidney J, et al. The cytotoxic T lymphocyte response to multiple hepatitis $B$ virus polymerase epitopes during and after acute viral hepatitis. J Exp Med 1995; 181:1047-58.

21 Webster GJ, Reignat S, Brown D, et al. Longitudinal analysis of CD8+ T cells specific for structural and nonstructural hepatitis $B$ virus proteins in patients with chronic hepatitis $B$ : implications for immunotherapy. J Virol 2004;78:5707-19.

22 Kakimi K, Isogawa $M$, Chung J, et al. Immunogenicity and tolerogenicity of hepatitis B virus structural and nonstructural proteins: implications for immunotherapy of persistent viral infections. J Virol 2002;76:8609-20. 